NASA/CR—2003-212545

\title{
Performance of the NASA Digitizing Core-Loss Instrumentation
}

Janis M. Niedra

QSS Group, Inc., Cleveland, Ohio 
Since its founding, NASA has been dedicated to the advancement of aeronautics and space science. The NASA Scientific and Technical Information (STI) Program Office plays a key part in helping NASA maintain this important role.

The NASA STI Program Office is operated by Langley Research Center, the Lead Center for NASA's scientific and technical information. The NASA STI Program Office provides access to the NASA STI Database, the largest collection of aeronautical and space science STI in the world. The Program Office is also NASA's institutional mechanism for disseminating the results of its research and development activities. These results are published by NASA in the NASA STI Report Series, which includes the following report types:

- $\quad$ TECHNICAL PUBLICATION. Reports of completed research or a major significant phase of research that present the results of NASA programs and include extensive data or theoretical analysis. Includes compilations of significant scientific and technical data and information deemed to be of continuing reference value. NASA's counterpart of peerreviewed formal professional papers but has less stringent limitations on manuscript length and extent of graphic presentations.

- TECHNICAL MEMORANDUM. Scientific and technical findings that are preliminary or of specialized interest, e.g., quick release reports, working papers, and bibliographies that contain minimal annotation. Does not contain extensive analysis.

- CONTRACTOR REPORT. Scientific and technical findings by NASA-sponsored contractors and grantees.
- CONFERENCE PUBLICATION. Collected papers from scientific and technical conferences, symposia, seminars, or other meetings sponsored or cosponsored by NASA.

- SPECIAL PUBLICATION. Scientific, technical, or historical information from NASA programs, projects, and missions, often concerned with subjects having substantial public interest.

- TECHNICAL TRANSLATION. Englishlanguage translations of foreign scientific and technical material pertinent to NASA's mission.

Specialized services that complement the STI Program Office's diverse offerings include creating custom thesauri, building customized databases, organizing and publishing research results ... even providing videos.

For more information about the NASA STI Program Office, see the following:

- Access the NASA STI Program Home Page at http://www.sti.nasa.gov

- E-mail your question via the Internet to help@sti.nasa.gov

- Fax your question to the NASA Access Help Desk at 301-621-0134

- Telephone the NASA Access Help Desk at 301-621-0390

- Write to:

NASA Access Help Desk

NASA Center for AeroSpace Information 7121 Standard Drive

Hanover, MD 21076 
NASA/CR-2003-212545

AIAA-2003-5972

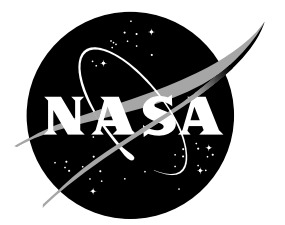

\section{Performance of the NASA Digitizing Core-Loss Instrumentation}

Janis M. Niedra

QSS Group, Inc., Cleveland, Ohio

Prepared for the

First International Energy Conversion Engineering Conference cosponsored by the American Institute of Aeronautics and Astronautics (AIAA), the American Society of Mechanical Engineers (ASME), and the Institute of Electrical and Electronics Engineers (IEEE)

Portsmouth, Virginia, August 17-21, 2003

Prepared under Contract NAS3-00145

National Aeronautics and

Space Administration

Glenn Research Center 


\section{Acknowledgments}

This work was sponsored by the NASA Glenn Research Center under contract NAS3-00145, with G.E. Schwarze as the Project Manager.

Trade names or manufacturers' names are used in this report for identification only. This usage does not constitute an official endorsement, either expressed or implied, by the National Aeronautics and Space Administration.

Available from

NASA Center for Aerospace Information 7121 Standard Drive

Hanover, MD 21076
National Technical Information Service 5285 Port Royal Road Springfield, VA 22100

Available electronically at http:/ /gltrs.grc.nasa.gov 


\title{
PERFORMANCE OF THE NASA DIGITIZING CORE-LOSS INSTRUMENTATION
}

\author{
Janis M. Niedra \\ QSS Group, Inc. \\ Cleveland, Ohio 44135
}

\begin{abstract}
The 'standard method' of magnetic core loss measurement was implemented on a high frequency digitizing oscilloscope in order to explore the limits to accuracy when characterizing high $Q$ cores at frequencies up to $1 \mathrm{MHz}$. This method computes core loss from the cycle mean of the product of the exciting current in a primary winding and induced voltage in a separate flux sensing winding. It is pointed out that just $20 \%$ accuracy for a $\mathrm{Q}$ of 100 core material requires a phase angle accuracy of $0.1^{\circ}$ between the voltage and current measurements. Experiment shows that at $1 \mathrm{MHz}$, even high quality, high frequency current sensing transformers can introduce phase errors of a degree or more. Due to the fact that the $\mathrm{Q}$ of some quasilinear core materials can exceed 300 at frequencies below $100 \mathrm{kHz}$, phase angle errors can be a problem even at $50 \mathrm{kHz}$. Hence great care is necessary with current sensing and ground loops when measuring high $\mathrm{Q}$ cores. Best high frequency current sensing accuracy was obtained from a fabricated 0.1-ohm coaxial resistor, differentially sensed. Sample high frequency core loss data taken with the setup for a permeability-14 MPP core is presented.
\end{abstract}

\section{MAGNETIC MATERIALS DEVELOPMENT AND CORE-LOSS INSTRUMENTATION}

Magnetically soft materials having very low core loss at frequencies up to a $\mathrm{MHz}$ are of great value in aerospace power conversion applications, where bulk and mass are critical. At high frequencies, lower specific losses enable the reduction of bulk and mass of magnetic components, while remaining within specified temperature rise limits. Presently, solid-state device (transistors, thyristors, diodes) switching losses in kilowatt level converters limit these frequencies to a few hundred $\mathrm{kHz}$, but a rise in frequency is sure to follow the arrival of better switches. A significant, if slow, response in the past 2 decades has been the development of amorphous and partially recrystallized magnetic ribbons based on iron and cobalt, whose improvement continues to this day. And the future may bring bulk new materials based on a composition of nanometer-sized particles that are electrically isolated, but magnetically 'exchange field' coupled, to reduce losses.
Progress in such materials development is difficult and depends both on innovative materials nanostructuring and the ability to accurately characterize incremental improvements. Accurate measurement of high frequency core loss at B-field levels found in real applications is fraught with a number of spurious influences that are fundamental and difficult to control, yet can induce hidden errors of the order of tens of percent. This paper presents the author's experience with a well-established measurement method set up on a high-speed digitizing oscilloscope and discusses the performance of several current probes at high frequency, with reference to characterizing a high Q core.

\section{THE 'STANDARD METHOD' OF CORE LOSS MEASUREMENT AND ITS LIMITATIONS}

In this widespread and relatively easy to set up method of taking magnetic core loss [1, 2], the magnetic induction in the core under test is driven to a desired amplitude by current in a primary winding and the value of this induction is measured by integrating the output of a secondary winding that senses the induced voltage. The average core loss is simply the timeaverage of the instantaneous product of the primary current $\mathrm{i}(\mathrm{t})$ and a voltage $\mathrm{v}(\mathrm{t})$, which is the secondary voltage multiplied by the winding turns ratio $\mathrm{N}_{1} / \mathrm{N}_{2}$. Winding $\left(\mathrm{N}_{1}\right)$ losses are automatically excluded. The hysteresis loop is correctly shown by the data. And robust, bench-top power amplifiers are available that, with proper tuning of the $\mathrm{N}_{1}$ circuit, can drive test sized cores $(\sim$ an inch OD) to high flux levels at even a megahertz. These are great advantages of this 'standard' method, as compared to the various commercial impedance analyzers and bridges, which can put out at most a few volts and lump both core and winding losses.

\section{Phase shift errors due to high frequency reactances}

False time shifts between signals representing the exciting current and induced voltage introduce an increasing fractional error in the measured time-average loss power $\overline{\mathrm{P}}=\overline{\mathrm{v}(\mathrm{t}) \mathrm{i}(\mathrm{t})}$, as $\overline{\mathrm{P}}$ decreases. In the language of linear circuits, a low power loss can be described by 
a small phase shift $\delta$ away from $\pi / 2$ of the phase angle $\theta$ between the voltage and current. With the subscript $p$ denoting peak values of sinusoidal quantities,

$$
\overline{\mathrm{P}}=(1 / 2) \mathrm{V}_{\mathrm{p}} \mathrm{I}_{\mathrm{p}} \cos \theta=(1 / 2) \mathrm{V}_{\mathrm{p}} \mathrm{I}_{\mathrm{p}} \sin \delta
$$

is the average power and hence the fractional error is

$$
\mathrm{d} \overline{\mathrm{P}} / \overline{\mathrm{P}}=(\cot \delta) \mathrm{d} \delta \approx \mathrm{d} \delta / \delta,
$$

where $\mathrm{d} \delta$ is the error in phase. Clearly, the effects of $\mathrm{d} \delta$ become rapidly worse as $\delta \rightarrow 0$.

Loss angle measurement accuracy requirements can become quite severe in practical cases of low loss inductors. For example, inductors based on certain lower permeability moly permalloy powder (MPP) cores can exceed a quality factor "Q" $(\mathrm{Q} \equiv \tan \theta)$ of 300 , at least when operating below $100 \mathrm{kHz}$. Noting that

$$
\mathrm{Q}=\cot \delta \approx 1 / \delta,
$$

a Q of 100 implies that $\delta=0.57^{\circ}$ ! From Equation (2), the fractional accuracy for measurement of power can be written as

$$
\mathrm{d} \overline{\mathrm{P}} / \overline{\mathrm{P}}=\mathrm{Q} \mathrm{d} \delta
$$

Even though at $1 \mathrm{MHz}$ the MPP material has higher losses than cobalt-based amorphous tape, due to much lower permeability ( $\mu_{\mathrm{r}}$ as low as 14 available for MPP), the MPP can achieve a much higher Q. The well-known figure of merit formula

$$
\mu_{\mathrm{r}} \mathrm{Q}=\pi \mathrm{fB}_{\mathrm{p}}^{2} /\left(\mu_{0} \overline{\mathrm{p}}\right)
$$

where $B_{p}$ is the peak B-field and $\bar{p}$ is the average volume-specific core loss, shows this; the reader can find derivations of Q-related formulas in [3].

Assuming a $\mathrm{Q}$ of 10 , an error $\mathrm{d} \delta=\pi / 180\left(=1^{\circ}\right)$ gives already a fairly large error $\mathrm{d} \overline{\mathrm{P}} / \overline{\mathrm{P}}=0.17$ in loss measurement. Maintaining a fractional degree phase accuracy may be feasible at tens of $\mathrm{kHz}$, but it is unrealistic with the present setup at $1 \mathrm{MHz}$, due to spurious phase shifts.

Spurious phase shifts arise mostly from inductive and capacitive effects, making high frequency by far the largest contributing factor to such errors. Their primary seats appear to be in the current probes and winding capacitances. The latter cause undesirable couplings that are case dependent and difficult to analyze. Differential sensing of the $\mathrm{N}_{2}$ voltage is used in the present instrumentation to reduce the effects arising from capacitive coupling to $\mathrm{N}_{1}$. Likewise, differential sensing of certain current probing devices was found to give values significantly different from those obtained by single-ended sensing, when measuring low loss cores.

\section{Limits to loss measurement resolution}

There exist low loss core materials that have, by design, a lowered permeability. When cycling to a given $\mathrm{B}_{\text {peak }}$, cores made of such materials store much more magnetic energy than they dissipate and hence are said to have a high Q. All instruments that derive power loss from simultaneous voltage $v(t)$ and current $i(t)$ records have the problem of resolving the time-average of the instantaneous power $P(t) \equiv v(t) i(t)$ from the peak value $P(t)_{p}$. And $Q$ is a direct measure of the severity of this problem.

In the case of a quasilinear magnetic material excited sinusoidally, an expression for Q in terms of the peakto-peak and average $\mathrm{P}(\mathrm{t})$ waveform properties is [3]

$$
\mathrm{Q}=\left[\left(\frac{\mathrm{P}(\mathrm{t})_{\mathrm{p}-\mathrm{p}}}{2 \overline{\mathrm{P}}}\right)^{2}-1\right]^{1 / 2}=\left[\left(\frac{\mathrm{V}_{\mathrm{p}} \mathrm{I}_{\mathrm{p}}}{2 \overline{\mathrm{P}}}\right)^{2}-1\right]^{1 / 2} .
$$

Measuring a Q of 100 core material thus amounts to accurately resolving an amplitude of 1 out of 100 . A standard 8-bit digitizer resolution (1 part in $2^{8}$ ) may seem inadequate for this. However, using the statistics of a large number of data points in the averaging interval (always an integral number of cycles of the excitation waveform) compensates for this problem. Obviously, digitizers that are both fast and accurate are helpful, but expensive.

A comparably significant problem related to resolution in the high $\mathrm{Q}$ case is the accurate setting of the averaging time interval. If the waveform is generated by an accurate source, such as a digitally synthesizing waveform generator, then the period is accurately known and cursors for the interval can be set accordingly. Alternatively, the period must be measured by the recorder itself, which brings in both waveform noise and digitizer resolution. Averaging over a number of records has been found to help, as that smoothes the waveform and improves accuracy of the determination of the zero point crossing. Least squares fitting of a straight line to the waveform points in the region of the zero crossing has been tried in another core loss instrumentation program and appeared to be beneficial. 
This requires processing by software external to the recorder and has not been implemented here.

\section{SERIOUS ERRORS IN CURRENT PROBES}

Phase shifts in the current probes have been the dominant source of error in the present instrumentation, when measuring low loss cores at frequencies in the hundreds of $\mathrm{kHz}$. Experimental evidence is that at high frequencies there is no uniform ground potential anywhere in the circuit comprised of the digitizing oscilloscope, the probes and the core windings. Ground loop differential potentials can be sufficient even along the ground returns of the oscilloscope probes to cause a degree or more of phase shift error. Based on this evidence, the following precautionary measures and solutions have been taken:

1. All signals are preferably connected to the recording oscilloscope by identical probes in order to avoid phase shift errors arising from differences in propagation time. Most frequently, the $10 \mathrm{X}$ attenuating, Tektronix type P6139A was used. However, observations indicate that 2 to 3 feet of a 50- $\Omega$ coaxial cable, such as the RG58AU, can perhaps be used, with negligible phase error at $1 \mathrm{MHz}$, to connect a Pearson type 2878 or 2877 current transformer directly to the scope. The cable of coarse gives a higher signalto-noise ratio.

2. Capacitive displacement currents induced in the casing of a current transformer, which is connected to the low side of a scope channel, may cause a small phase error. The conductor whose current is being sensed can be the source of such displacement currents, if it rides at a high level, alternating potential relative to ground. Therefore it is best to either ground this conductor, or else bring the oppositely swinging current return conductor to the proximity of the casing. The magnitude of this error has not been fully investigated.

3. Lack of a uniform ground potential and resulting ground loop currents can cause seemingly mysterious phase errors, when single-ended sensing. Therefore the voltage across a resistor used to sense the primary current was always sensed differentially by simply differencing the 2 channels involved. The ground clips of the scope probes were then connected to each other only and not to anything else. The (usually low ohms) resistor itself must be kept at a low potential, by say a ground cable connected to the chassis of the scope. Failure to do this correctly can result in both phase errors of several degrees and unacceptably high common mode potentials on the 2 channels

4. Common mode potentials that cause sensing problems can involve the driving amplifier itself. These spurious modes were greatly reduced by a common mode choke, built on a very low loss, cobalt-based, amorphous tape core. The bifilar winding was made up from 8 turns of a coaxial cable. And the core was of the VAC type $6025 \mathrm{~F}$ material.

5. At frequencies above $100 \mathrm{kHz}$, current transformers can introduce a degree or two of phase shift error. Therefore in high-Q cases, it was found best to avoid the use of current transformers, in favor of a coaxial resistor to do the current sensing. Even though the current transformers may be rated tens of $\mathrm{MHz}$ (Pearson 2878: $70 \mathrm{MHz}$, Pearson 2877: $200 \mathrm{MHz}$ ) for the amplitude $3 \mathrm{db}$ down point, the phase accuracy is usually not specified. Indeed, a phase differential exceeding 2 degrees was observed between the outputs of the above-mentioned transformers at $1 \mathrm{MHz}$. For a $\mathrm{Q}$ of 50, this is nearly a factor of 2 uncertainty in the measured power loss! A comparative discussion is given below.

\section{Evidence for superior accuracy when using a coaxial resistor}

The resistance of carbon composition resistors is known to be constant up to many $\mathrm{MHz}$, making them in principle useful for the present current sensing application. However, to make any resistor acceptable for core current sensing, both its ohmic value and impedance angle (primarily inductive) must be controlled to sufficiently low values. Larger ohmic values clearly reduce the inductance problem. However, even a value exceeding $1 \Omega$ can be too large when testing lower permeability cores that require relatively large exciting fields, as the resistive voltage drop, interacting with core nonlinearities, can distort the flux density waveform. Moreover, a resistive voltage drop can significantly 'Q-spoil' the resonance, when a low loss capacitor is used in parallel with the primary winding to supply the reactive current. Note that the sensing resistor must be in the resonant loop of this well-known and very effective method to supply large reactive currents to quasi-linear cores. Unfortunately, smaller ohmic values enhance the inductance problem to an unacceptable level, even before the signal-to-noise ratio becomes too low, unless a geometry is implemented to reduce magnetic field coupling. A 
rough estimate of the severity of the angle problem can be had as follows.

In the Kelvin sensing configuration, the inductive coupling of a simple, axial-lead resistor to its voltage sensing circuit can be minimized by enclosing the resistor in a snug tube that carries the return current (the tube is connected to one of the leads of the resistor). Ideally, the magnetic field outside of this tube vanishes. One sensing lead exits the tube through a hole, while the other sensing lead is connected to the junction of the resistor lead and tube. Hence this is just a shielded resistor equipped with sense leads. For simplicity of magnetic field computation, let the resistor and leads be considered as a conductive cylinder of radius $r_{0}$ and let the tube be very thin and of radius $r_{1}$. An elementary magnetic field computation over the two cylindrical volumes shows that the inductive coupling per unit length to the sense leads is

$$
\mathrm{L} / \ell=\frac{\mu_{0}}{2 \pi}\left(\frac{1}{2}+\ln \frac{\mathrm{r}_{1}}{\mathrm{r}_{0}}\right)
$$

A realistic, $2 \mathrm{~W}$ rated, carbon resistor with shield might have dimensions $r_{0}=1 \mathrm{~mm}, r_{1}=4 \mathrm{~mm}$ and be about $20 \mathrm{~mm}$ long. Hence $10^{-8} \mathrm{H}$ would be a representative magnitude for its inductance, giving an inductive reactance of $2 \pi 10^{-2} \Omega$ at $1 \mathrm{MHz}$. If the resistance were $1 \Omega$, then the impedance angle would be 3.6 degrees. Clearly, such a phase angle error is unacceptable when measuring high $Q$ core materials. A $10 \Omega$ value (phase error thus reduced to 0.36 degrees) might be useable for low to moderate $\mathrm{Q}$ cases, with low exciting current. Otherwise the only known recourse in resistive current sensing is the coaxial geometry, which eliminates magnetic coupling by placing the sense leads along the axis of symmetry of a cylindrical resistor configuration. Inductive coupling can thereby be reduced sufficiently to maintain high frequency accuracy with fractional ohm values.

A coaxial resistor was fabricated by arranging 10 identical, parallel connected, axial lead, carbon resistors on a cylindrical surface of $7.75 \mathrm{~mm}$ radius. One set of the leads was connected to each other by a copper disk (a penny with holes drilled for the leads) and the other 10 leads were soldered into 10 holes on a $7.75 \mathrm{~mm}$ radius circle drilled in a $5 / 8$ inch copper pipe end cap. A short piece of 5/8-inch pipe and another end cap completed the outer shell. Current and sense connections were brought out by BNC type connectors, centrally mounted in the end caps. Each $1 / 2 \mathrm{~W}$ resistor had a value of about $1.1 \Omega$, making up a coaxial resistor of $0.112 \Omega$, measured at DC.
Figure 1 is a scope trace of two current transformer outputs compared to each other and to the output of the above coaxial resistor. The resistor signal is vertically centered on the central horizontal line of the graticule, whereas the transformer outputs are slightly shifted up and down to show phase shift differentials. All 3 devices carry the same $1 \mathrm{MHz}$ current of about $1.5 \mathrm{~A}$ peak. Regardless of the accuracy of the coaxial resistor, it is apparent that the transformer outputs have a phase differential of about 2.3 degrees. One transformer output leads (Pearson 2878) and the other one lags (Pearson 2877) the output of the coaxial resistor by about 1.2 degrees. If the coaxial resistor output is accurate as to phase, then both transformers are poor for measuring the losses in high Q cores at $1 \mathrm{MHz}$, with the phase leading transformer giving inflated losses. At the time of this report, the accuracy of the coaxial resistor's output was unknown, except that a similar trace comparison at $1 \mathrm{MHz}$ to a $10-\Omega$ shielded resistor showed no discernible phase shift. This suggests an error bound of less than about $1 / 2$ a degree.

\section{SAMPLE PLOTS OF CORE LOSS}

Core loss instrumentation based on the Tektronix model TDS 7104 high frequency $(1 \mathrm{GHz})$ oscilloscope was applied to measuring the losses of a permeability-14, MPP core (an Arnold type B-063010-4). All scope probes were 10X passive (Tektronix model P6139A) and the current probe was mainly the above-described $0.112 \Omega$ coaxial resistor. Since 10 -turn windings were used on this low permeability core, the high exciting currents (over 50 A peak in some cases) could only be obtained by means of the resonating technique. A core of this type can exhibit a high $\mathrm{Q}$, mainly because for a given peak flux density $B_{p}$, the energy storage per unit volume $\left(\frac{1}{2 \mu} B_{p}^{2}\right)$ is high, again due to the low permeability. Loss characterization curves for this core are presented in Figure 2 and are generally somewhat below the manufacturer's catalog data. Loss data taken for this core using a Pearson model 2878 (leads) current transformer tended to be roughly twice as high, even down to frequencies much below the highest frequency. A likely explanation is that at lower frequencies, the increased Q of the core countered the decreased phase error of the current transformer. Indeed, along the $800 \mathrm{kHz}$ curve, the Q held roughly constant at 30 , but along the $50 \mathrm{kHz}$ curve, the $\mathrm{Q}$ varied from 340 at $0.005 \mathrm{~T}$ to 150 at $0.11 \mathrm{~T}$. 


\section{SUMMARY AND CONCLUSIONS}

The 'standard method' of magnetic core loss measurement was implemented on a high frequency digitizing oscilloscope in order to explore the limits to accuracy when characterizing high $Q$ cores at frequencies up to $1 \mathrm{MHz}$. This quite old method merely averages, over an integral number of cycles, the product of the exciting current in a primary winding and the induced voltage in a flux sensing winding to find the average loss power. Serious error problems can arise when this straightforward method is applied to cores having a $\mathrm{Q}$ in the tens or even higher at high frequencies. These problems can arise even at frequencies below $100 \mathrm{kHz}$, where certain core materials can have a $\mathrm{Q}$ exceeding 300 ! The fractional error in power for small errors $\mathrm{d} \delta$ in the measurement of the phase shift (away from $90^{\circ}$ ) between the current and voltage turns out to be the product of $\mathrm{Q}$ and $\mathrm{d} \delta$, where $\mathrm{d} \delta$ is in radians. As an example, for a $\mathrm{Q}(=\cot \delta)$ of 100 , the $\delta=0.57^{\circ}$ and hence the error bounds on phase measurement become extreme $\left(0.057^{\circ}\right.$ to $\left.0.11^{\circ}\right)$ to get just a 10 to $20 \%$ accuracy in power. Hence at high frequencies, when spurious phase shifts of several degrees can easily occur, special precautions are necessary to get even a coarse measurement of the average power. Waveform amplitude and period measurement errors are mentioned in relation to vertical channel resolution, but with modern equipment their effects on the average power reading are negligible compared to the effects of a likely phase error at high Q.

Currents induced in ground loops were identified as seriously contributing to phase errors of a degree or so when precautions in grounding are not taken. The lack of a uniform ground potential anywhere at $1 \mathrm{MHz}$ appeared to be the basic cause of such errors. This problem was greatly reduced by differentially sensing (simple channel subtraction, with probe grounds clipped only to each other) both the induced voltage and the signal from any current sensing resistor. Such differential sensing gave good results, provided any common mode voltages were kept low.

Phase differentials over 2 degrees were observed at $1 \mathrm{MHz}$ between the outputs of two current transformers rated up to 70 and $200 \mathrm{MHz}$, which is evidence for caution when using such transducers in the high Q case, even at frequencies far below their rated frequency.
The most accurate current transducer appeared to be a fractional ohm coaxial resistor, fabricated from 10 carbon resistors connected in parallel and arranged on the surface of a circular cylinder. The outer shell was a short piece of 7/8-inch copper pipe, with corresponding copper end caps. Connections were brought out through BNC type connectors installed in the end caps. In this well-known configuration, inductive coupling to the output is very small, due to the cylindrical symmetry. A broad range of resistance values, from about $0.1 \Omega$ up, can be easily constructed in this way. A $0.112 \Omega$ resistor was built here for application to core loss measurement. Only indirect evidence for the superior phase performance of this coaxial resistor could be obtained, because commercial instrumentation for the measurement of the extremely low inductance of such a low value resistor at $1 \mathrm{MHz}$ is not readily available.

Using the above coaxial resistor, core loss data were obtained from $50 \mathrm{kHz}$ to $800 \mathrm{kHz}$ for a permeability-14 MPP core, which is capable of exhibiting extreme values of $\mathrm{Q}$. The values obtained are somewhat less than those given in the manufacturer's catalog and only about $1 / 2$ of the values obtained by using a current transformer (Pearson 2878), which is known to have a slight leading phase error. The persistence of this ratio of 2 down to $50 \mathrm{kHz}$ may be due to the Q of over 300 there.

\section{REFERENCES}

1. V.J. Thottuvelil et al., "High-Frequency Measurement Techniques for Magnetic Cores", IEEE Power Electronics Specialists Conference, June 1985, pp. 412-425.

2. W.R. Wieserman et al., "High Frequency, High Temperature Specific Core Loss and Dynamic B-H Hysteresis Loop Characteristics of Soft Magnetic Alloys", 25th Intersociety Energy Conversion Engineering Conference, Reno, NV, August 1990. Also NASA TM-103164.

3. J.M. Niedra and G.E. Schwarze, "Wide Temperature Magnetization Characteristics of Transverse Magnetically Annealed Amorphous Tapes for High Frequency Aerospace Magnetics”, 34th Intersociety Energy Conversion Engineering Conference, Vancouver, BC, Canada, August 1999. Also NASA TM-209298. 


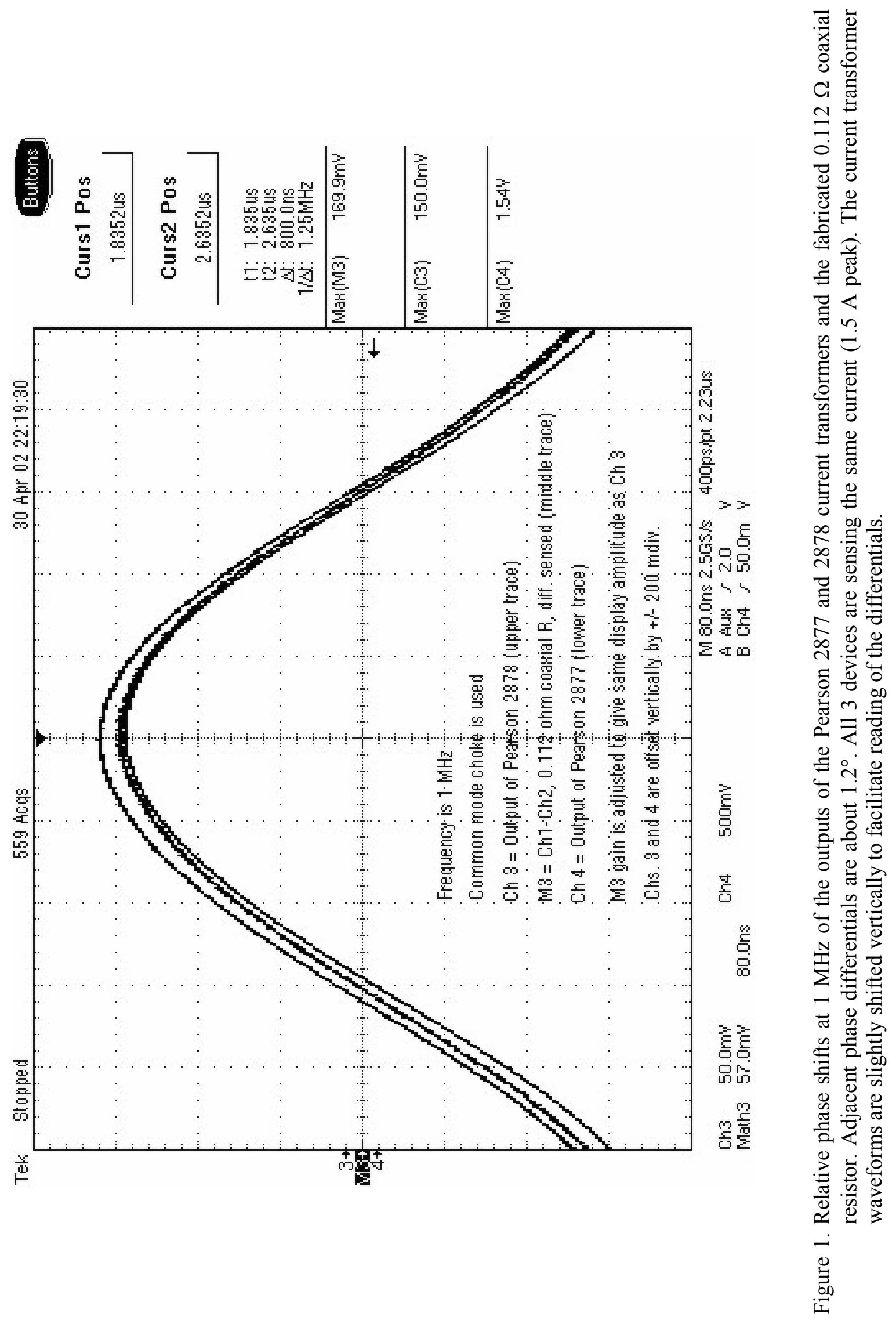



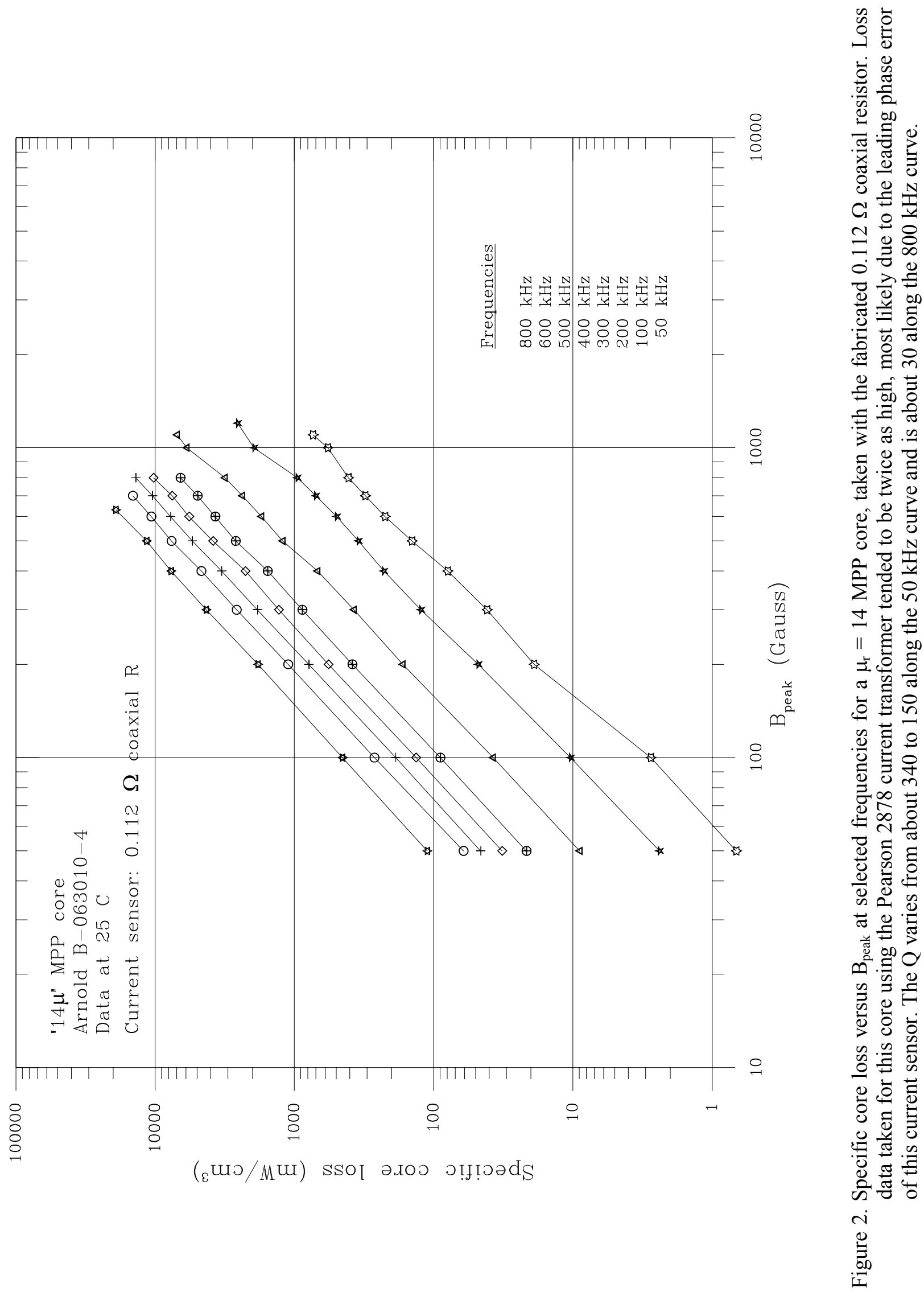


\section{APPENDIX A}

\section{NOTES ON DATA PROCEDURES}

\section{Burst mode}

Application of the excitation voltage in short bursts spaced relatively far apart in time, or as just a single burst, effectively reduces core heating due to the core loss to a negligible value. This is the simplest way to maintain temperature stability when testing a core under conditions that produce a high loss.

The present setup uses a pulse generator to "gate" a signal generator that drives a power amplifier. The pulse width thus fixes the burst duration and the pulse repetition rate fixes the duty cycle. A very sharp "sync" pulse, available at the start of each gating pulse, is input as an external trigger signal to a Tektronix TDS7104 digitizing scope, which is operated in a triggerableafter-delay mode. This delay time is adjustable and very stable. The actual sweep trigger is then taken from one of the signal channels. By adjusting the delay time to be slightly less than the duration of the burst, one or more cycles of the signal can be selected near the end of the burst and recorded. This trigger mode, as opposed to a simple delayed trigger, is essential to improve signal stability for purposes of averaging in the presence of instabilities, such as frequency fluctuations and longduration transients associated with the start of a burst.

\section{Signal averaging}

With all 4 channels in use, the $2.5 \times 10^{9}$ samples/second digitizer rate for each channel of the TDS7104 permits up to 2500 data samples per cycle of a $1 \mathrm{MHz}$ signal. Due to the availability of this high density in time of data samples, signal averaging will not normally improve the accuracy of averages computed over a given time interval set by cursors. That is, in a computation of averages over a cycle, the high density of data samples averages out even relatively large amplitude random noise on a low level signal. However, a smooth signal is necessary for accurate, onthe-fly computation by the scope of quantities dependent on level crossings (period, cycle mean) and also for visualizing plots, such as B versus $\mathrm{H}$ hysteresis loops.

Long duration spurious transients in the burst mode can create troublesome waveform distortions. Such transients arise from inductances of output coupling transformers used with the power amplifier, from any tuning capacitors used to help drive low- $\mu$ cores, from common-mode or ground-loop interactions with the driving amplifier, etc. and are the downside of the burst mode of testing. In effect, the transient modulations prevent the B-field in the core from traversing a stationary B-H loop. A transient whose amplitude is still significant near the end of the burst may be acceptable, provided its frequency is low compared to that of the signal. On the time scale of a cycle or two of the signal, the modulation then appears merely as dc offsets in the voltage and current signals that can be subtracted out by math routines and the B-H loop is essentially closed. However, it may not be advisable to signal average when the bursts have non-repetitive, but otherwise acceptable, modulations, for then the trigger point will fluctuate. Hence before taking data, the signal burst should be examined overall for unacceptable transients, especially if there are signs of a fluctuating trigger point or signal amplitude in the data window.

\section{Baseline restoration}

Acceptable forms for the recorded secondary winding induced voltage and the primary winding exciting current are taken to be

$$
\begin{aligned}
& v(t)=v_{\tau}(t)+v_{0}, \\
& i(t)=i_{\tau}(t)+i_{0},
\end{aligned}
$$

where $v_{\tau}$ and $i_{\tau}$ are periodic functions of zero cycle mean and $\mathrm{v}_{0}$ and $\mathrm{i}_{0}$ are essentially constants. The $\mathrm{v}_{\tau}$ represents the ideal voltage, as applied by the power amplifier, and $\mathrm{v}_{0}$ accounts for any voltage-offset error in the scope channel and also for any local (in time), real offset due to a slowly oscillating transient. The terms in Equation (A2) are given a similar interpretation. A blocking capacitor was used to eliminate a real dc offset from the power amplifier.

Regardless of cause, the offsets contribute $\mathrm{v}_{0} \mathrm{i}_{0}$ to the computed cycle-mean power $\overline{\mathrm{vi}}$. If the offsets are merely zero-level errors in the channel amplifiers, then a correction for the offsets gives the true power loss. But if $\mathrm{v}_{0}$ is a real applied voltage, such as due to slow oscillations in the burst, then the magnetic flux in the core will be ratcheting and the B-H loop will not close. In this case, the power $\mathrm{v}_{0} \mathrm{i}_{0}$ is tentatively assumed to go into the changing average field energy of the core, providing a rationale for still making the correction. The accuracy of this may be questionable, for a magnetic core is generally a non-linear device. Questions of validity aside, offset corrections were never seen to be very significant for the data taken. Since the cycle means $\mathrm{v}_{0}=\overline{\mathrm{v}}$ and $\mathrm{i}_{0}=\overline{\mathrm{i}}$ are easily computed on-the-fly, scope math routines were applied to recover $\mathrm{v}_{\tau}$ and $\mathrm{i}_{\tau}$. The core loss was then identified with $\left(\mathrm{N}_{1} / \mathrm{N}_{2}\right) \overline{\mathrm{v}_{\tau} \mathrm{i}_{\tau}}$. 


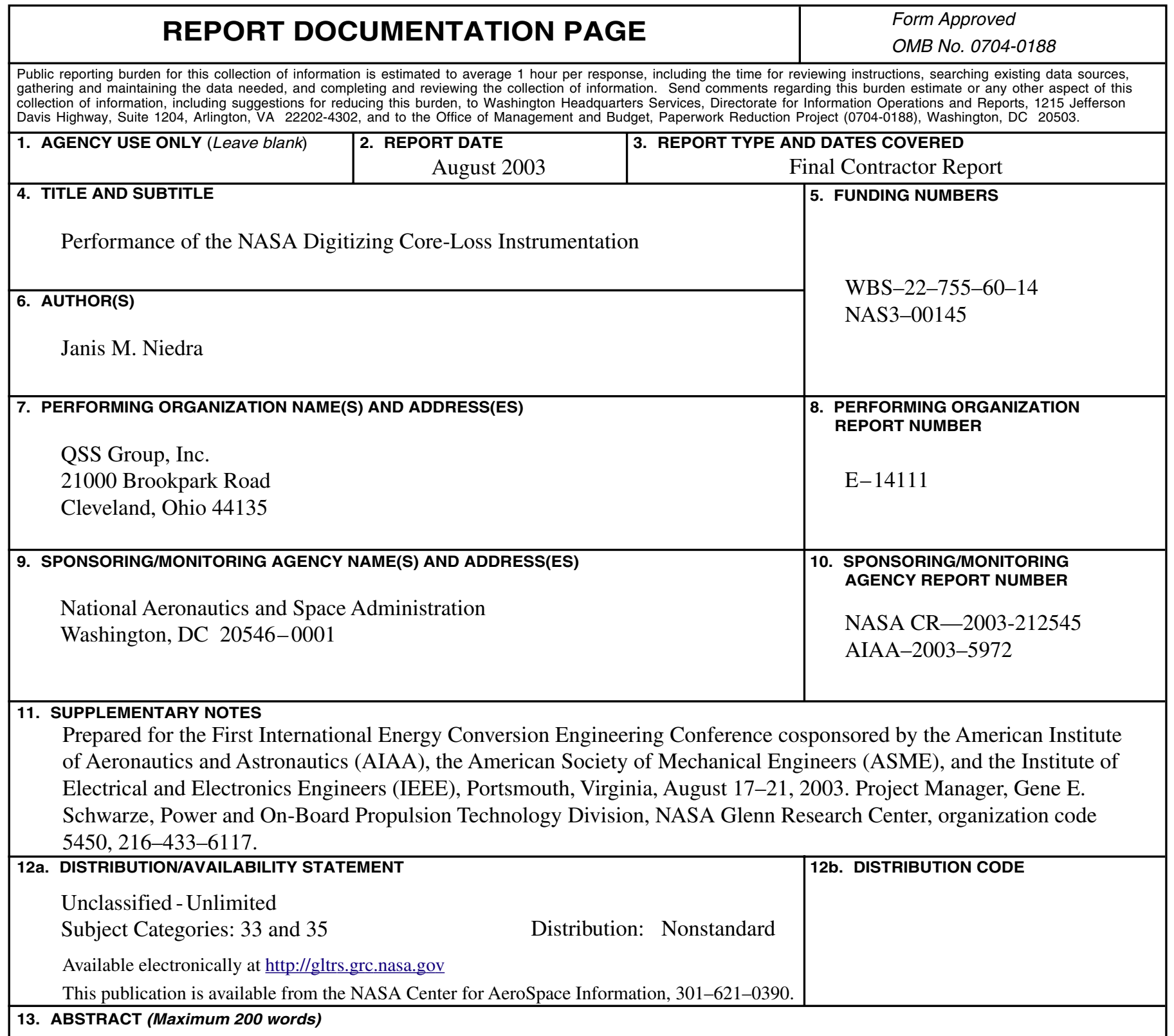

The 'standard method' of magnetic core loss measurement was implemented on a high frequency digitizing oscilloscope in order to explore the limits to accuracy when characterizing high Q cores at frequencies up to $1 \mathrm{MHz}$. This method computes core loss from the cycle mean of the product of the exciting current in a primary winding and induced voltage in a separate flux sensing winding. It is pointed out that just 20 percent accuracy for a $\mathrm{Q}$ of 100 core material requires a phase angle accuracy of $0.1^{\circ}$ between the voltage and current measurements. Experiment shows that at $1 \mathrm{MHz}$, even high quality, high frequency current sensing transformers can introduce phase errors of a degree or more. Due to the fact that the $\mathrm{Q}$ of some quasilinear core materials can exceed 300 at frequencies below $100 \mathrm{kHz}$, phase angle errors can be a problem even at $50 \mathrm{kHz}$. Hence great care is necessary with current sensing and ground loops when measuring high Q cores. Best high frequency current sensing accuracy was obtained from a fabricated 0.1-ohm coaxial resistor, differentially sensed. Sample high frequency core loss data taken with the setup for a permeability-14 MPP core is presented.

\begin{tabular}{|c|c|c|c|}
\hline & \multirow{2}{*}{\begin{tabular}{|c|} 
15. NUMBER OF PAGES \\
14
\end{tabular}} \\
\hline \multicolumn{3}{|c|}{$\begin{array}{l}\text { 14. SUBJECT TERMS } \\
\text { Core loss; Magnetic instrumentation; High-Q material; Current sensing; Phase shift errors }\end{array}$} & \\
\hline $\begin{array}{l}\text { 17. SECURITY CLASSIFICATION } \\
\text { OF REPORT } \\
\text { Unclassified }\end{array}$ & $\begin{array}{l}\text { 18. SECURITY CLASSIFICATION } \\
\text { OF THIS PAGE } \\
\text { Unclassified }\end{array}$ & $\begin{array}{l}\text { 19. SECURITY CLASSIFICATION } \\
\text { OF ABSTRACT } \\
\text { Unclassified }\end{array}$ & \\
\hline
\end{tabular}

